\title{
ISOLATION OF NUCLEAR POWER PLANTS FROM
}

\author{
EARTHQUAKE ATTACK
}

\author{
R. I. Skinner, R. G. Tyler and S. B. Hodder*
}

\begin{abstract}
$\underline{\text { ABSTRACT }}$
The analysis of one-mass and two-mass models indicates that the earthquake-generated horizontal forces and deformations of the main structures of a nuclear power plant can be reduced by a factor of about ten times by mounting the overall power plant building on a recently developed base-isolation system. The very high forces which the

'resonant appendage' effect may induce in some critical components (such as fuel elements, control rods and essential piping) may be reduced by a factor of 40 or more times by the isolation system. The parameters of the isolation system have been chosen as appropriate to the level of protection which should be provided for a nuclear plant in a seismically active area. Consideration is given to flexible mounts and dampers suitable for such an isolator.
\end{abstract}

\section{INTRODUCTION}

It is difficult to provide adequate earthquake resistance for nuclear power plants located in seismically active areas. Since the consequences of earthquake induced damage or malfunction may be very serious it is necessary to make provision for very severe earthquakes, with recurrence intervals of many thousands of years. Within the framework of present knowledge this implies maximum horizontal accelerations and velocities in excess of one " $\mathrm{g}$ " and $2.0 \mathrm{~m} / \mathrm{s}$ respectively, for a site in an area of high seismicity.

When a non-isolated nuclear power plant is subjected to the vibratory forces imposed by an earthquake, its dynamic response is very complex. To ensure a low probability of failure, important plant components are designed to remain elastic and hence they vibrate with low self-damping. Again, to ensure a low likelihood of damage to interconnecting components and of malfunction of mechanisms, the main substructures of the plant are designed with high rigidities and hence with short periods. The combination of short period and low self-damping results in large dynamic magnifications of the applied earthquake forces since they correspond to the severe range of the response spectra of appropriate design earthquakes.

A particularly severe situation arises when a small but very important component of a nuclear plant, such as a fuel element, control rod, or essential pipe, has a natural period which is close to that of the supporting structure. Such resonant appendages may be subjected to accelerations which are 20 or more times the maximum ground acceleration. Owing to uncertain natural periods, particularly when component restraint is rendered non-linear by clearances to accommodate thermal and other expansions, difficulties are encountered when attempts are made to detune such resonant appendages.

* Physics and Engineering Laboratory, D.S.I.R., Lower Hutt.
In conventional design it is possible to fit flexible pipework with dampers and to attenuate the forces on some important subsidiary structures by supporting them on flexible mounts and dampers. However, a number of the most important flexible components, such as fuel rods, are inaccessible to dampers. Again, when a mount for a subsidiary structure provides a high level of earthquake attenuation it also allows large horizontal displacements, making such isolation impractical for the most important units with their interconnecting pipework and other services.

The difficulties inherent in attempting to protect individual components of a nuclear plant may be avoided by installing an earthquake attenuating system under the overall plant(1). Earlier proposals by other designers to provide earthquake attenuation for major structures have proved impractical since adequate dampers were not available and undamped flexible mounts would allow excessive displacements and the quasiresonant build-up of large forces. The recent development of appropriate hysteretic dampers $(2,3,4)$ leads to practical baseisolation systems for various types of structure. These dampers may be combined with mounts which provide horizontal flexibility, together with a centring force. A flexible mount which is suitable for a nuclear power plant may be provided by sets of laminated rubber pads of the type frequently used to support bridge spans (5)

Recently developed hysteretic dampers, appropriate for use in a base-isolated nuclear power plant, utilize the plastic deformation of solid steel beams, or the cyclic extrusion of lead. Designs are developing rapidly and dampers intended specifically for use with nuclear power plants are under consideration. One particular system which may be used is discussed below. It utilizes laminated rubber mounts, tapered-beam flexural dampers, and is provided with back-up skids which would provide support and a measure of base isolation in the very unlikely situation 
of the mounts being damaged by excessive horizontal motions, or by vertical deformation of the foundations.

\section{APPROXIMATE EARTHQUAKE RESPONSE OF A BASE-ISOLATED NUCLEAR POWER PLANT}

The principal consequences of base isolation, in terms of earthquake induced loads and deformations, have already been described (I). For completeness, and to allow further discussion, the most important results are reproduced below.

As a first step the earthquake response is computed for a single mass resonator, Fig. 1, with and without base isolation. The resonator and isolator parameters are defined in Figs. 1 and 2 , where it is seen that the set of hysteretic dampers is modelled by a pair of linear springs and a coulomb damper which give a bilinear approximation to the damper forces. Values chosen for the mount and damper parameters were established as effective during exploratory calculations. Moreover, isolator components with these parameters can be provided readily.

Earthquake responses were computed for the following normalized parameter values;

$\mathrm{K}_{\mathrm{b}} / \mathrm{W}=0.25 \mathrm{~m}^{-1}, \mathrm{~K}_{\mathrm{c}} / \mathrm{Q}_{\mathrm{c}}=11 \mathrm{~m}^{-1}, \mathrm{k}_{\mathrm{c}} / \mathrm{Q}_{\mathrm{c}}=0.75 \mathrm{~m}^{-1}$

$\mathrm{K} / \mathrm{W}$ was varied to give non-isolated periods from 0 to 1.0 seconds

$\zeta$ was chosen to give a damping factor of 5 웅

The base shears computed for a baseisolated system, under an earthquake of 4 times that at El Centro $1940 \mathrm{~N}-\mathrm{S}$, are shown in Fig. 3 where they are seen to be virtually independent of period, and to have values of about 0.1 of the base shears for corresponding non-isolated systems. The displacements of the isolated base were approximately constant at $0.55 \mathrm{~m}$.

The effects of varying the overall damping, $Q_{C} / W$, are shown in Figs. 4 and 5. It is seen that the amount of hysteretic damping required to minimize the base shear is higher for the very severe earthquakes. Base displacements are always reduced by increased damping.

The responses of a resonant appendage, with and without base isolation, were explored by introducing the small mass $W_{a}$ and spring shown dotted in Fig. 1. The stiffness of the small spring was chosen to give the appendage the same natural period (on a rigid base) as that of the non-isolated main structure; and hence the most severe resonant condition. A viscous damping factor of $3 \%$ was provided. The maximum accelerations of the appendage, with and without base isolation, are shown in Fig. 6 for four times the "El Centro" earthquake accelerations. It is seen that the appendage loads are typically reduced by about 40 times with the introduction of base isolation.

The single mass resonator of $\mathrm{Fig} .1$ is an extreme simplification of the multimass base-isolated power plant. When a comprehensive set of masses is used for analysis the loads on some will exceed the loads derived from the single-mass analysis.
Present indications are that typical increases will be in the range of $20 \%$ to $40 \%$ for the main structure, while in the extreme case of resonant appendages the increase may exceed 100\%. Subsidiary structures which have a mass which is a very small fraction of the overall plant mass will behave essentially as appendages, and will be subjected to corresponding loads. Heavy subsidiary structures will incur load factors which are intermediate between those for the main structure and those for appendages. When a plant is not isolated many of the masses are subject to earthquake loads which are much higher than those given by the acceleration of the single mass resonator of Fig. 3. Moreover, foundation flexibility may make an important contribution to the loads. The increase for major masses is up to about $100 \%$ with a corresponding increase in the acceleration of a resonant appendage mounted on such a mass. Hence for many masses the ratios between the loads for non-isolated and isolated plants may be even greater than those implied by Figs. 3 and 6 .

Current analysis will result in a more detailed comparison between loads on multimass systems, with and without base isolation. These results are being computed 1 for a range of design earthquakes.

The representation of a hysteretic damper by a bilinear loop of constant parameters is an oversimplification. For a typical steel-beam damper the value of $Q_{C}$ increases and the value of $\mathrm{k}_{\mathrm{C}}$ decreases with an increased range of deformation. Moreover, for varying amplitudes of cyclic deformation, each half-cycle is influenced by the previous half-cycle. From Fig. 4 it is seen that the increasing $Q_{C}$ value should allow a better compromise between provisions for earthquakes of intermediate and of high severity. The overall hysteresis forces can be further modified to give a better balance between the provisions for earthquakes of different severities by using a mix of dampers with different elastic ranges, or by using stops to control the range over which different dampers operate. A mix of steel-beam and lead-extrusion dampers should give improved overall hysteretic forces with a minimum of mechanical complexity.

A further consequence of the bilinear hysteretic model of the damper is that it provides greater centring forces than those provided by the damper itself. Hence care must be taken to ensure that the overall centring action of the isolator is adequate.

The base isolator does not reduce vertical earthquake forces. However these are normally lower than horizontal forces, and moreover most parts of a structure have high strength and low deformability under vertical loads. With greatly reduced horizontal loads other components may be re-oriented to increase their resistance to vertical loads.

\section{BASE ISOLATOR COMPONENTS}

It has been shown that a high level of earthquake protection can be provided by using isolator components with the overall stiffness and hysteresis values assumed in the previous section. The hysteresis values 
are typical of those for flexural beam dampers with maximum strains of about $3 \%$. With this maximum strain occurring during a design earthquake, the damper deformation capacity is sufficient to withstand about 20 such events.

A damper suitable for use in a nuclear plant isolator is shown in Fig. 7. It is based on two steel beams of uniform thickness. Each beam has its width reducing towards the ends to give a nominally uniform curvature under transverse end loads.

These dampers may be built with an effective damping force $Q_{C}$ of between 5,000 and 10,000 $\mathrm{kN}$, and with an operating displacement of plus and minus 0.6 metres. Unlike the dampers described previously (1), they can be installed within a convenient base to foundation separation of 2 metres. No difficult fabrication process is required. the largest task being the formation of the double taper from a rectangular beam. This would probably be done by torch cutting and surface grinding. The appendix gives the derivation of the damper dimensions required to give an effective damper force $Q_{C}$ of $8,000 \mathrm{kN}$ and an operating stroke of plus and minus 0.6 metres.

A flexible mount with a strong centring action may be provided by sets of 12 laminated rubber pads as shown in Fig. 7 . With pad dimensions of $0.75 \times 0.75 \times 0.2 \mathrm{~m}$ the maximum rubber strain is limited to $100 \%$ for a translation of $0.6 \mathrm{~m}$. The interleaved platforms provide stability and reduce the loss of effective supporting area for each pad. When typical bridge pads are used (5), and loaded by a weight to give the recommended working stress, then the ratio of load to stiffness is $0.25 / \mathrm{m}$ for a stack height of $0.6 \mathrm{~m}$. This was the ratio adopted for the above analysis. The total load capacity of the set of 12 pads is given as $16,000 \mathrm{kN}$

While there are other isolator components which may be used to provide the necessary lateral flexibility, centring forces, and hysteretic damping, those described are capable of providing effective and reliable earthquake isolation at moderate cost.

\section{A BASE-ISOLATED NUCLEAR POWER PLANT}

The use of the base isolator components may be illustrated by applying them to a proposed power plant used in earlier studies (1). This plant encloses twin reactors and the turbine and generator halls within a single rigid building. The weight of the plant is $5 \times 10^{6} \mathrm{kN}$ and its estimated cost, in 1974, was U.S. \$1000 million.

With a load capacity of $16,000 \mathrm{kN}$ per mount, 312 mounts are required. Since the density of mounts required will be proportional to the concentration of power plant weight, this will lead naturally to horizontal stiffnesses which are balanced with respect to the centre of gravity of the power plant.

Dampers are chosen to provide forces which are 0.15 times the power plant weight for each horizontal direction: to achieve the base shears and displacements given by the vertical dotted lines in Figs. 4 and 5 (for the single-mass model). Hence the total damper force required is $0.3 \mathrm{~W}$ or $1.5 \times 10^{6} \mathrm{kN}$. With the $8000 \mathrm{kN}$ dampers considered in the appendix 188 dampers are required. When locating the dampers it is necessary to ensure force balance with respect to the centre of gravity of the plant for each horizontal axis. It is convenient to utilize the pillars on which the dampers are mounted as emergency supports against the very small likelihood of mount damage or excessive foundation deformation, Fig. 7 These pillars would be faced with a material which provides a reasonably controlled frictional force which should continue to give considerable base isolation during the extremely severe earthquakes which might call them into play.

\section{GENERAI CONSIDERATIONS}

It has been shown that practical isolators of the type described provide nuclear power plants with a high measure of isolation from horizontal earthquake forces. During the very severe earthquakes considered the forces on major parts of the power plant are reduced to about one tenth of those which would occur if the plant was not isolated and its deformations remained elastic. The force reductions which may be achieved for resonant appendages, which might include such important components as fuel rods, control rods and essential piping, may be up to 40 or more times. Moreover the reduced forces are cyclic with long periods so that isolation greatly reduces the number of load reversals during an earthquake.

The reduced loads achieved with base isolation should lead to much greater safety under severe earthquake attack. Moveover shuldowns due to earthquakes would be much less frequent, and the power plant should be in a condition for prompt restarting after the most severe attack.

The isolator components would be designed and tested for what are considered to be the worst possible earthquake forces. However. should much worse occur, a high reserve of protection is provicied by the "skids" which would take over from the flexible mounts for inconceivably large horizontal displacements or vertical deformations of the foundations. The dampers would continue to operate for a number of cycles for deformations much greater than the design values.

By siting the plant on strong stiff ground such as rock, the earthquake ground motions would be limited to those with relatively low energy in the longer period components and are hence most severely attenuated by base isolation. Moreover such ground is least subject to vertical deformations which, if excessive, may reduce the efficiency of the base isolator.

It would be necessary to introduce appropriate flexibility into the connections for external services, including cooling water supplies and electric power lines. Adequate emergency cooling water should be provided within the reactor building.

\section{DISCUSSION}

Base isolation should provide a greater degree of safety under earthquake attack than would be provided in a non- 
isolated plant. With isolation the design loads and deformations are not only greatly reduced but are rendered insensitive to assumptions about the character of the attacking earthquakes and the dynamic character of the power plant, as determined by its structural and mechanical detail. With isolation it should be possible to limit structural and component deformations within the plant to the elastic range, for which their performance is more reliable and better known.

The isolator components can be constructed to have a proven reserve of performance for which they can be exhaustively tested under service conditions. Moreover the installed-isolator components have a high level of redundancy.

Base isolation may be applied to existing power plant designs at a moderate increase in cost, but greater effectiveness and economy would be achieved if the proposed base isolation system were taken into account at all stages of the design of the power plant for earthquake resistance.

\section{REFERENCES}

1. Skinner, R. I., Bycroft, G. N., and McVerry, G. H., "A Practical System for Isolating Nuclear Power Plants from Earthquake Attack", Nuclear Engng. and Design, 1976, 36, 287-297.

2. Skinner, R. I., KelIy, J. M. and Heine, A. J., "Hysteretic Dampers for Earthquake-Resistant Structures", Int. J. Earthq. Engng. Struct. Dyn., 1975, $3,287-96$.

3. Robinson, W. H., and Greenbank., L. R., "An Extrusion Energy Absorber Suitable for the Protection of Structures During an Earthquake", Int. J. Earthq. Engng. Struct. Dyn., 1976, 4, 251-259.

4. Skinner, R. I., Heine,, A. J., and Tyler, R. G., "Hysteretic Dampers to Provide Structures with Increased Earthquake Resistance", To be published in Procs. 6th World Conference on Earthquake Engineering, 1977, Delhi, India.

5. Lindley, P. B., "Engineering Design with Natural Rubber", N.R. Tech. Bull., 1970, 3rd Edn. Natural Rubber Producers Association, London.

\section{APPENDIX}

The approximate design of two-beam tapered-cantilever dampers may be based on simple beam theory which gives, for a triangular cantilever of uniform thickness loaded at its apex,

$$
\begin{aligned}
Q_{C} & =\sigma_{0} b t^{2} / 41 \\
\varepsilon_{m} & =D t / I^{2} \\
\theta & =2 D / 1
\end{aligned}
$$

where $b, t, 1$ are the base width, thickness, and length of the cantilever; $\varepsilon_{\mathrm{m}}$ is the nominal maximum strain for a maximum vertex displacement $D ; \theta$ is the end rotation of the cantilever and $Q_{C}$ is the effective damper force. For a maximum strain $\varepsilon_{\mathrm{m}}$ of 0.03 the effective yield stress $\sigma_{0}$ is approximately equal to $275,000 \mathrm{kN} / \mathrm{m}^{2}$.
Consider the beam dimensions required to give an effective damper force $Q_{C}$ of $8,000 \mathrm{kN}$ for maximum displacements of plus and minus $0.6 \mathrm{~m}$, with a maximum strain $\varepsilon_{\mathrm{m}}$ of approximately 0.03 and an end rotation of less than 20 degrees.

Each tapered cantilever must provide a force $Q_{C}$ of $4,000 \mathrm{kN}$ and undergo a maximum displacement $D$ of $0.3 \mathrm{~m}$.

$$
\begin{aligned}
& \text { Try } \quad I=2 \mathrm{~m}, b=1.0 \mathrm{~m}, t=0.35 \mathrm{~m} . \\
& \text { Then } \\
& \qquad Q_{C}=4210 \mathrm{kN}, \varepsilon_{\mathrm{m}}=0.026, \theta=17.2^{\circ}
\end{aligned}
$$

If the taper is replaced by a uniform width of $0.3 \mathrm{~m}$ beyond the point at which it reaches this value, as for the damper shown in Fig. 7 above, the volume of beam available for plastic deformation is reduced by about 108 which would result in a maximum strain $\varepsilon_{m}$ of about 0.029 .

Before design of a prototype damper, more precise values would be obtained for the damper parameters, based on cyclic tests on small scale models utilizing specimens of the steel beams to be used in the full scale dampers. 


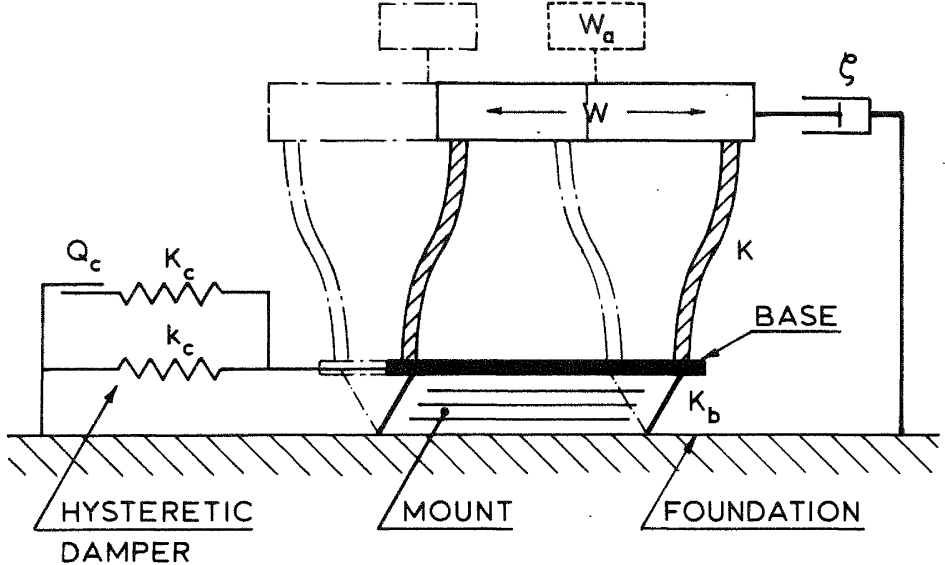

FIGURE 1:

MODEL OF A STRUCTURE WITH BASE ISOLATOR.

$W=$ WEIGHT OF MASS;

$\mathrm{K}=$ SPRING STIFFNESS

$\zeta=$ VISCOUS DAMPING FACTOR

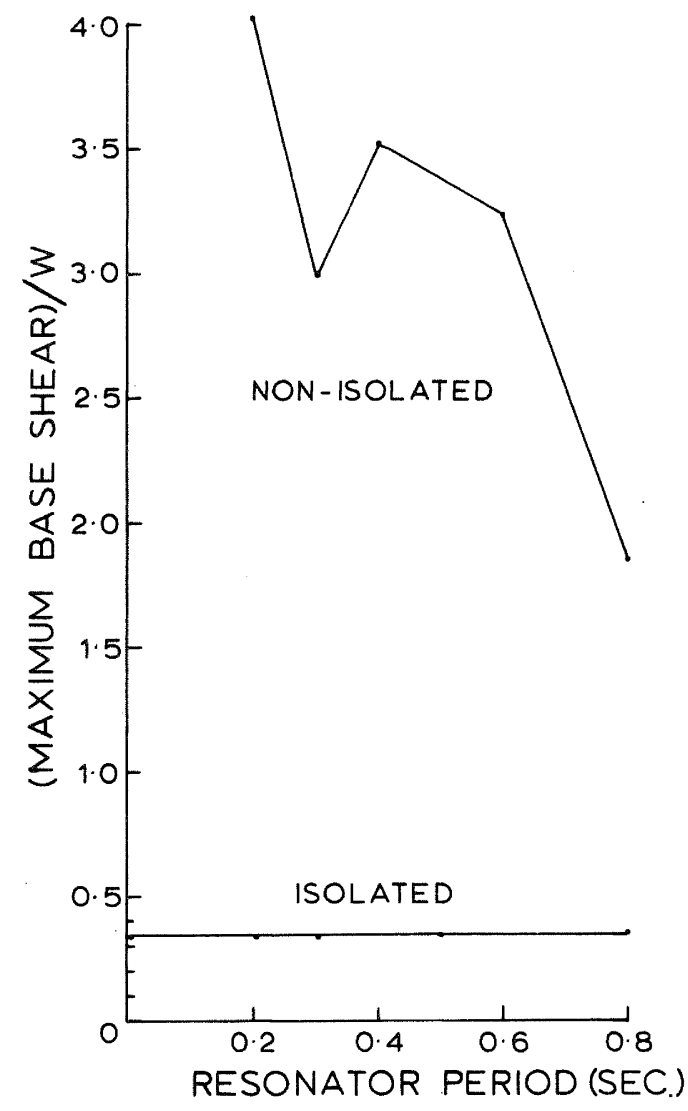

FIGURE 3:

RESPONSE OF A SINGLE-MASS RESONATOR, WITH AND WITHOUT A BASE ISOLATOR, TO 4 TIMES THE ACCELERATION AT EL CENTRO 1940 NS. DAMPING IN THE ELASTIC RANGE IS 0.05 OF CRITICAL.

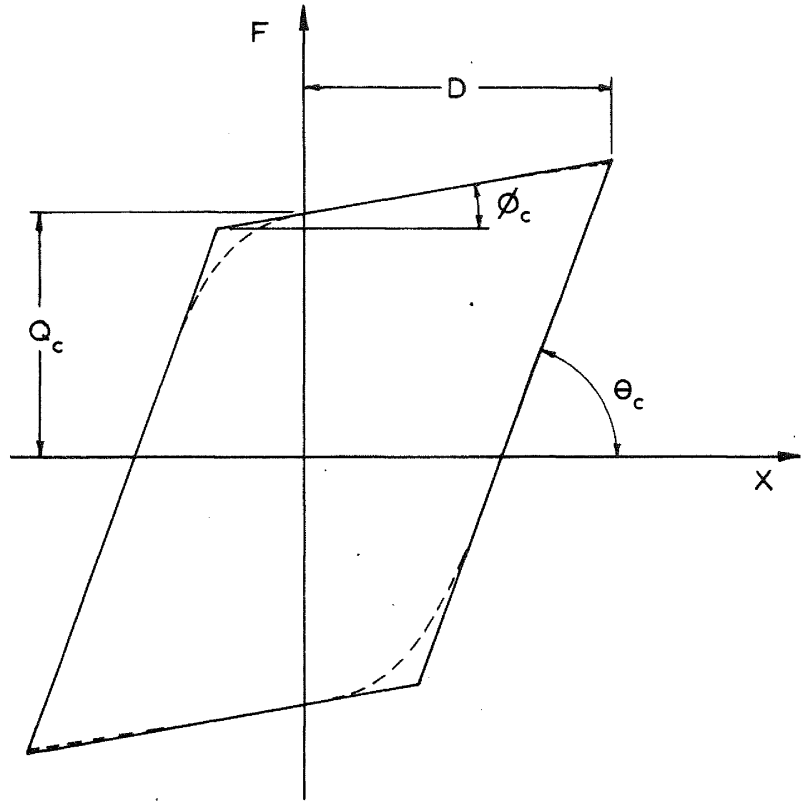

FIGURE 2:

BILINEAR APPROXIMATION TO THE CYCLIC LOAD-DEFLECTION RESPONSE OF THE HYSTERETIC DAMPER. $\mathrm{Q}_{\mathrm{C}}=$ DAMPER FORCE TANN $\theta_{C}=K_{C}+K_{c}=$ INITIAL DAMPER STIFFNESS

TAN $\phi_{c}=k_{c}=$ YIELDED DAMPER STIFFNESS

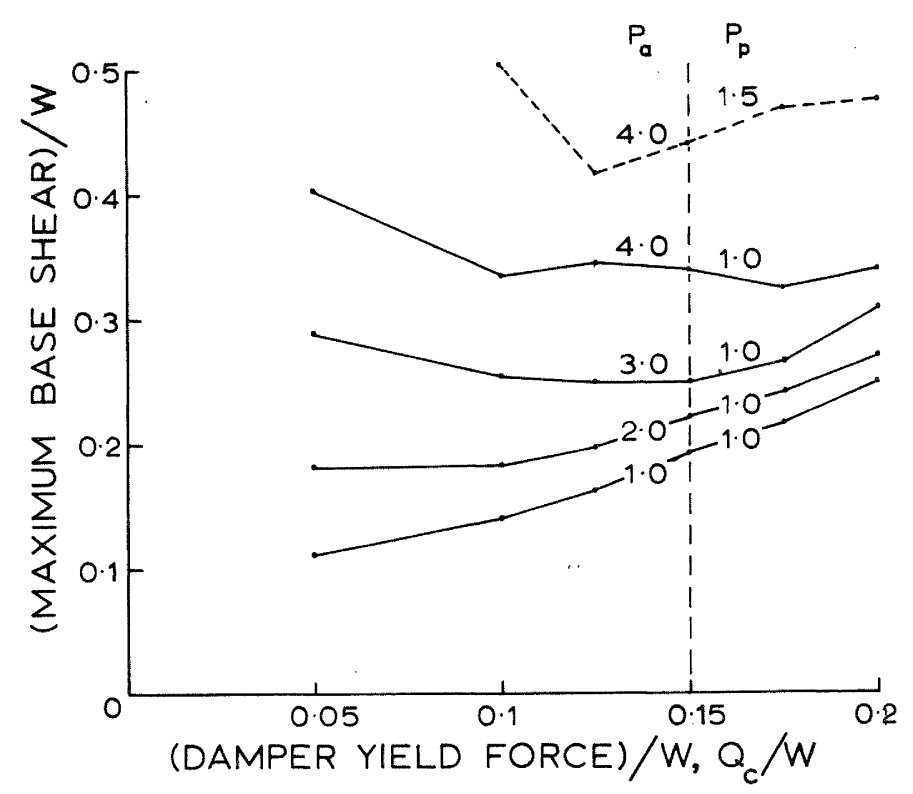

FIGURE 4:

SHEARS FOR BASE-ISOLATED RESONATORS WITH PARAMETERS GIVEN BY TABLE AND WITH A RESONATOR NON-ISOLATED PERIOD OF 0.3 SECONDS. ACCELERATIONS AT EL CENTRO 1940 NS WERE SCALED BY AMPLITUDE FACTOR $P_{a}$ AND TIME SCALE FACTOR $P_{p}$. 


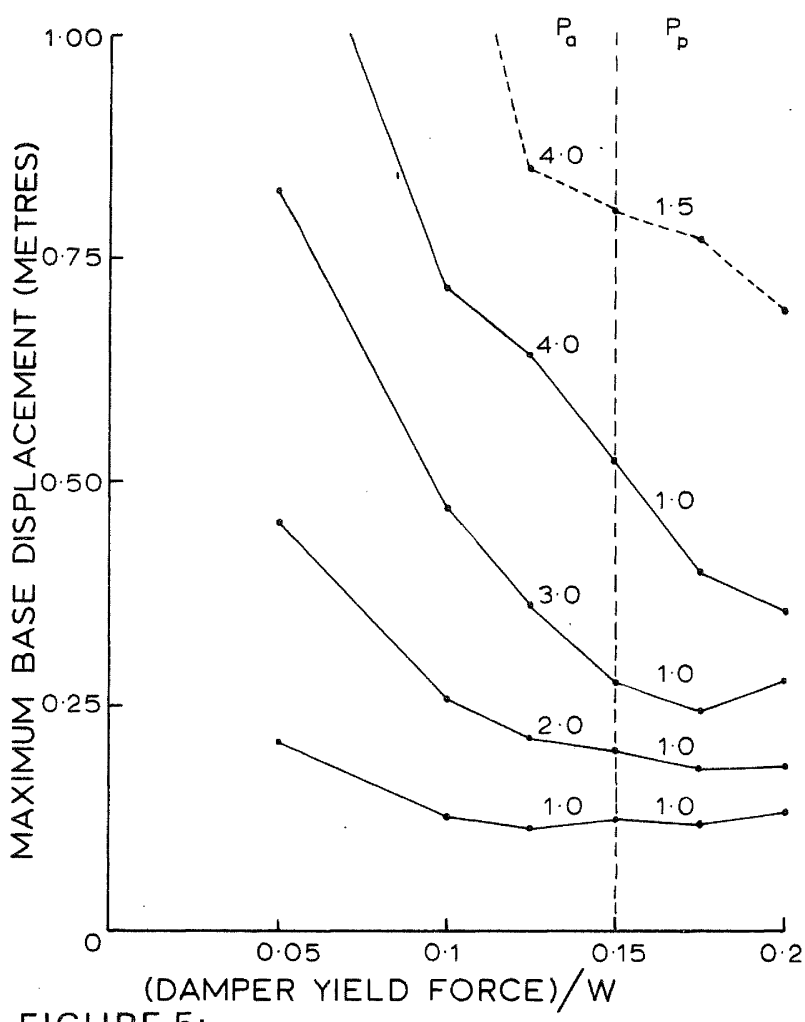

FIGURE 5:

DISPLACEMENTS FOR BASE-ISOLATED

RESONATORS WITH PARAMETERS GIVEN BY TABLE AND WITH A RESONATOR NON-ISOLATED PERIOD OF 0.3 SECONDS. ACCELERATION AT EL CENTRO 1940 NS WERE SCALED BY AMPLITUDE FACTOR $P_{a}$ AND TIME SCALE FACTOR $P_{p}$.

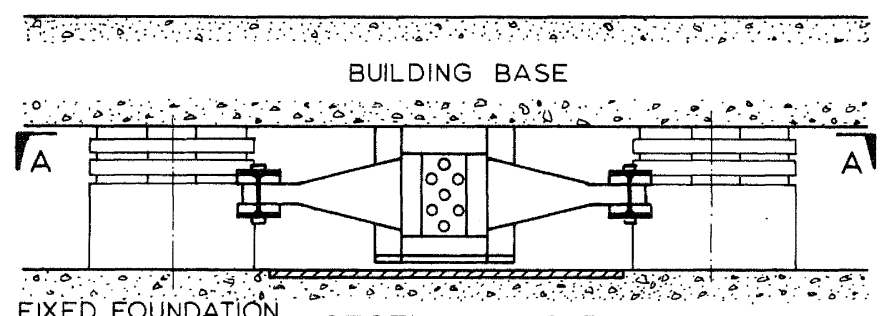
SECT' ELEV'B-B

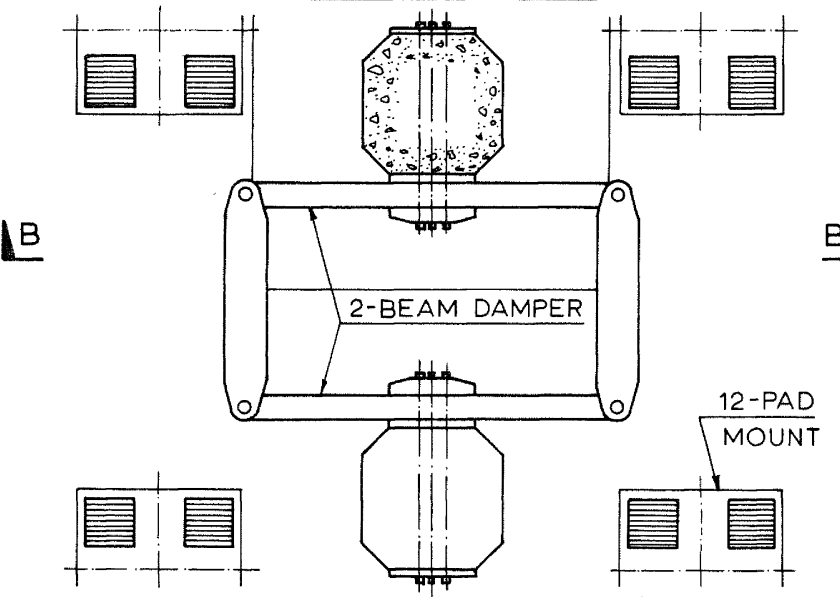

FIGURE 7: $\quad$ SECT' PLAN A-A

SCHEMATIC DIAGRAM OF A TWO-BEAM FLEXURAL DAMPER INSTALLED BETWEEN THE BASE OF A NUCLEAR PLANT BUILDING AND THE FOUNDATIONS ALSO SHOWN ARE THE ADJACENT HORIZONTALLY FLEXIBLE MOUNTS, EACH CONSISTING OF 12 LAMINATED RUBBER PADS.

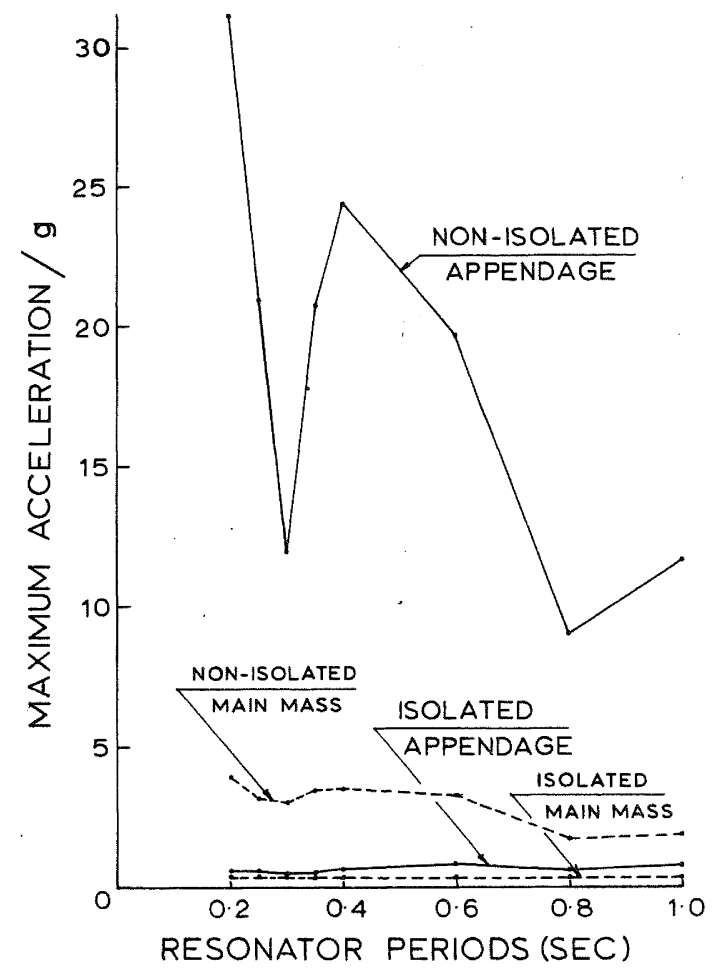

FIGURE 6:

RESONANT APPENDAGE ACCELERATION WITH AND WITHOUT ISOLATION OF THE MAIN RESONATOR.

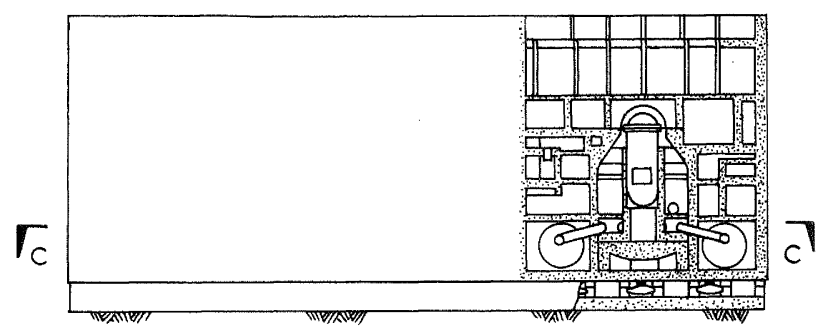

SECT:' ELEVV: D-D

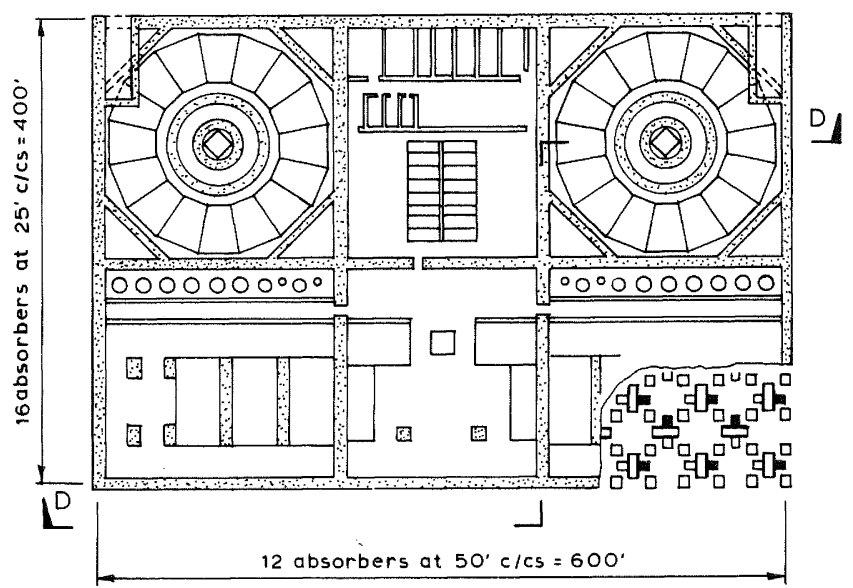

SECT.' PLAN C-C

FIGURE 8:

GENERAL LAYOUT OF THE FLEXIBLE MOUNTS AND HYSTERETIC DAMPERS INSTALLED UNDER A NUCLEAR POWER PLANT BUILDING. 